\title{
Determination of heat-mass transfer coefficients within the apparatuses with jet-film contact devices
}

\author{
Ilnur N. Madyshev ${ }^{1}$, Oksana S. Dmitrieva ${ }^{2}$, and Andrey V. Dmitriev ${ }^{2, *}$ \\ ${ }^{1}$ Kazan National Research Technological University, 420016 Kazan, Russia \\ ${ }^{2}$ Kazan State Power Engineering University, 420066 Kazan, Russia
}

\begin{abstract}
One of the ways of intensifying the heat and mass transfer processes in gas-fluid systems is designing jet-film contact devices with a developed surface of phase contact at high flow velocities. A contact jetfilm device has been developed. The results of numerical investigation of the operation of this device are presented. There were determined the coefficients of heat transfer to the air from the surface of liquid inside of the drain cup of contact device. The criterion equations of convective heat transfer for engineering calculations of jet-film contact devices is corrected.
\end{abstract}

\section{Introduction}

Various heat-mass transfer processes and apparatuses are widely used in chemical, petrochemical, energy and other industries [1-3]. Efficiency of these processes is mainly determined by improvement of the used contact devices. Moreover, material and energy costs significantly depend upon the design of contact device [4-6].

Most of the currently used tray and nozzle contact devices have the following disadvantages. Separation areas shall be provided within the tray column apparatuses, which significantly increase the volume of apparatus, without being the main zone of interaction of gas-liquid flows. Nozzle columns have an uneven distribution of liquid and gas phases in the cross section of working area, which significantly reduces the efficiency of heat-mass transfer processes. In addition, at high gas flow rates, there is a problem of liquid droplets entrainment that largely restricts the increase in efficiency of the current heat-mass transfer devices and can lead to the "choking" of the column.

\section{Description of jet-film contact device}

In order to eliminate the specified disadvantages, the authors developed the jet-film contact device for the heat-mass transfer apparatuses [7], shown in Fig. 1. The proposed device consists of parallel square drain cups $l$ with vertical walls, required for maintaining the

\footnotetext{
* Corresponding author: ieremiada@gmail.com
} 
liquid level inside of them. Vertical perforated baffles 2 are the supports for drain cups 1 and have slotted holes for the installation of appropriate drain cups 1 . The drain cups 1 are open from the top end, but recurved leaves 3 in the form of circular segments are executed in the bottom of cups. These segments are required for the liquid distribution over the surface of vertical perforated baffles 2 .

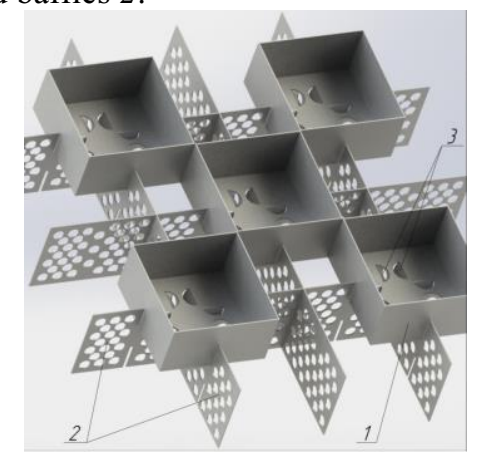

Fig. 1. Jet-film contact device: 1 - drain cup; 2 - baffles; 3 - recurved leaves.

The developed jet-film contact device operates as follows. Liquid, through the plurality of recurved leaves 3 , executed in the bottom of drain cups 1 , is dispersed in the form of jets to the below located vertical perforated baffles 2 . When liquid jets move along the surface of vertical baffles 2, the liquid is distributed with formation of a stable film flow. Thus, the coming down liquid film interacts with an ascending gas flow. After that the formed film, colliding with liquid surface inside of drain cups 1 , collapses. When distances between the drain cups, arranged at the same level, are equal to width of a drain cup, it provides stable, uniform gas flow, which leads to decrease in hydraulic resistance of the proposed jet-film contact device.

\section{Analysis of results of numerical studies}

An important step in the development of engineering methods for calculating the apparatuses with jet-film contact devices is to determine the heat-mass transfer coefficients from the flowing liquid film to the gas flow. In this regards, numerical studies were carried out by means of the software complex ANSYS Fluent, in which the interaction of the gas and liquid flows was simulated as exemplified by air-water system at the temperature of $20^{\circ} \mathrm{C}$. The device consisted of 3 contact stages and in course of studies, geometrical dimensions of device were changed in the scale, proportional to its characteristic dimensions, namely to the width of the drain cup, taken equal to $100 \mathrm{~mm}$ and height of the wall equal to $10 \mathrm{~mm}$. Moreover, actual gas rate was changed from 1 up to $20 \mathrm{~m} / \mathrm{s}$, which corresponded to the values of Reynolds number from $6.6 \cdot 10^{3}$ up to $6.0 \cdot 10^{5}$. The liquid level in the drain cup was taken as maximum.

In order to simulate the turbulent flows, modification of the two-parametric turbulence model k- $\omega$ SST, showing satisfactory conformance with experimental data, obtained in earlier studies, was used [8-10].

The research results showed that the well-known criterion equation for the case of liquid flow over the flat plate does not correctly describe the heat-mass transfer processes within the contact stage. The classical equation for determining the average heat transfer coefficient at turbulent air flow regime is the following [11, 12]:

$$
\mathrm{Nu}_{G}=0.032 \mathrm{Re}_{G}^{0.8}
$$


where $\mathrm{Nu}_{G}=\alpha l / \lambda-$ Nusselt number; $\alpha$ - heat transfer coefficient, $\mathrm{W} /\left(\mathrm{m}^{2} \cdot \mathrm{K}\right) ; l-$ characteristic linear dimension (length of the plate), $\mathrm{m} ; \lambda$ - heat conduction coefficient, $\mathrm{W} /(\mathrm{m} \cdot \mathrm{K}) ; \operatorname{Re}_{G}=W l / v_{G}-$ Reynolds number; $W-$ actual gas rate, $\mathrm{m} / \mathrm{s} ; v_{G}-$ coefficient of kinematic gas viscosity, $\mathrm{m}^{2} / \mathrm{s}$.

The diagram in Fig. 2 shows that an increase in actual gas rate and geometrical dimensions of contact device leads to increase in values of Nusselt number. However, regarding the heat transfer coefficient values, their highest values correspond to the low heat transfer surfaces. Thus, for example, decrease in the surface of vertical baffles by 4 times leads to an increase in the values of heat transfer coefficients by $10.8-37.5 \%$, depending on the actual gas rate.

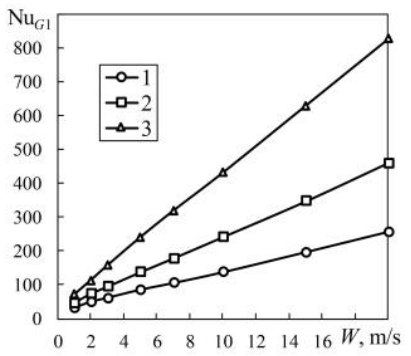

Fig. 2. Dependency of Nusselt number on actual gas rate at different geometrical constants of contact device $M_{b}: 1-0.5 ; 2-1 ; 3-2$.

Processing of the numerical simulation results allowed to correct the multiplier value and index of Reynolds number in the convective heat transfer equation in case of liquid flow over the flat plate for the jet-film contact device as follows:

$$
\mathrm{Nu}_{G 1}=0.0184 \operatorname{Re}_{G}^{0.8038}
$$

approximation accuracy coefficient of which was 0.9989 in the range of Reynolds numbers from $6.6 \cdot 10^{3}$ up to $6.0 \cdot 10^{5}$ (Fig. 3a). It shall be noted, that the width of drain cup was taken as characteristic linear dimension, equal to the length of plate.

In the course of numerical studies, there were also determined the coefficients of heat transfer to the air from the surface of liquid inside of the drain cup. Processing of the numerical simulation results allowed to obtain the following criterion equation:

$$
\mathrm{Nu}_{G 2}=0.0052 \mathrm{Re}_{G}^{0.8685},
$$

approximation accuracy coefficient of which was 0.997 in the range of Reynolds numbers from $6.6 \cdot 10^{3}$ up to $6.0 \cdot 10^{5}$ (Fig. $3 \mathrm{~b}$ ).
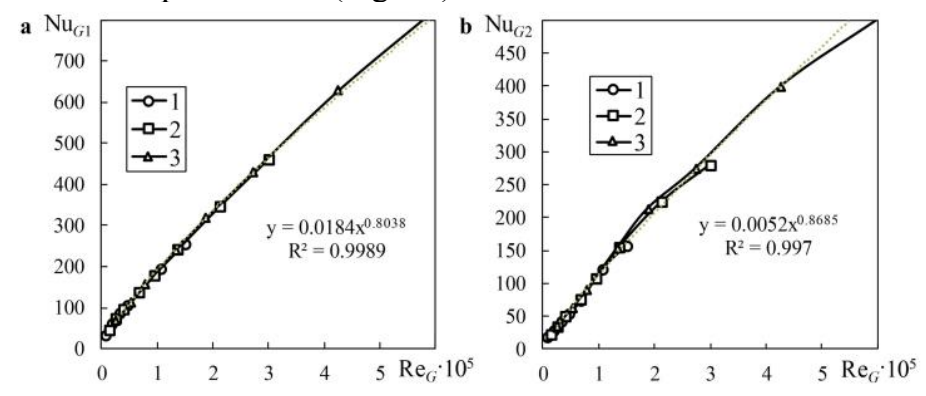

Fig. 3. Dependency of Nusselt number on Reynolds number at the heat transfer from the surface of vertical baffles (a) and from the surface of liquid inside of the drain cup (b) at different geometrical constants of contact device $M_{b}: 1-0.5 ; 2-1 ; 3-2$. 
Comparing the heat transfer coefficients from the surface of vertical baffles and from the surface of liquid inside of the drain cup, it can be seen that, upon other equal conditions, the heat transfer from the surface of the baffles is the most intensive. Thus, for example, when the width of drain cup is equal to $100 \mathrm{~mm}$, the heat transfer coefficients from the surface of vertical baffles by 1.54-2.08 times greater than the similar coefficients from the liquid surface depending on the Reynolds numbers taken.

The mass transfer coefficient in the gas phase can be determined on the basis of a wellknown Lewis analogy:

$$
\beta_{y}=\frac{\alpha}{\rho_{G} c_{p}}\left(\frac{\mathrm{Pr}}{\mathrm{Sc}}\right)^{2 / 3},
$$

where $\rho_{G}$ - gas density, $\mathrm{kg} / \mathrm{m}^{3} ; c_{p}$ - heat capacity at constant pressure, $\mathrm{J} /(\mathrm{kg} \cdot \mathrm{K}) ; \operatorname{Pr}=$ $v_{G} / a_{G}-$ Prandtl number; Sc $=v_{G} / D_{G}-$ Schmidt number; $a_{G}-$ temperature conductivity coefficient, $\mathrm{m}^{2} / \mathrm{s} ; D_{G}-$ diffusion coefficient, $\mathrm{m}^{2} / \mathrm{s}$.

\section{Conclusion}

Thus, it can be stated that the use of corrected criterion equations of convective heat transfer will improve the accuracy of engineering calculations for design of heat-mass transfer apparatuses with the proposed jet-film contact devices.

The reported study was funded by RFBR, according to the research project No. 16-38-60081 mol_a_dk.

\section{References}

1. Z. J. Wei, Z. L. You, S. Q. Gui, Ind. Eng. Chem. Res. 49, 3732 (2010)

2. K. Ponomarev, E. Orlova, D. Feoktistov, EPJ Web Conf. 110, 01060 (2016)

3. V. Maksimov, T. Sharifulin, L. Zhidkova, K. Eloyan, EPJ Web Conf. 159, 00033 (2017)

4. J. Mackowiak, Chem. Eng. Res. and Des. 89, 1308 (2011)

5. A. E. Orlando, L. C. Medina, M. F. Mendes, E. M. A. Nicolaiewsky, Braz. J. Chem. Eng. 26, 619 (2009)

6. G. Q. Wang, X. G. Yuan, K. Yu, Ind. Eng. Chem. Res. 44, 8715 (2005)

7. A. V. Dmitriev, O. S. Dmitrieva, I. N. Madyshev, A. N. Nikolaev, L. V. Kruglov, Patent RU No. 171022 (2017)

8. E. Maslov, I. Zharova, B. Borisov, N. Fedotova, EPJ Web Conf. 76, 01027 (2014)

9. B. V. Borisov, EPJ Web Conf. 110, 01012 (2016)

10. O. S. Dmitrieva, A. V. Dmitriev, I. N. Madyshev, A. N. Nikolaev, Chem. Pet. Eng. 53, 130 (2017)

11. G. V. Kuznetsov, J. Eng. Phys. Thermophys 89, 1241 (2016)

12. O. S. Dmitrieva, A. V. Dmitriev, L. V. Kruglov, Procedia Eng. 150, 753 (2016) 